\title{
Sinderos
}

\section{Lo nuevo y lo tradicional en educación: una oposición engañosa}

The new and the traditional in education: a deceptive opposition

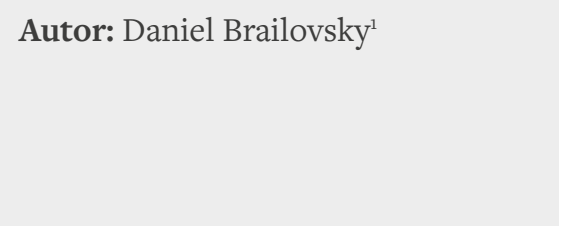

1. Correo electrónico: dbrailovsky@flacso.org.ar

\begin{abstract}
Resumen
En este artículo se ensaya un análisis de las categorías "tradicional" y "nuevo" empleadas para dar cuenta de posicionamientos pedagógicos, didácticos y educativos en general. Se parte de la hipótesis de que, bajo la falsa apariencia de un debate entre conservadurismo y progresismo, se simplifican cuestiones que ameritan un tratamiento más complejo y profundo. Se propone reconocer la heterogeneidad de visiones que se presentan como "críticas a la educación tradicional", donde conviven los ideales liberadores del escolanovismo de principios del siglo $\mathrm{XX}$ junto a otros discursos enunciados desde las reformas neoliberales, de rasgos eficientistas, neurocientíficos y moralizantes.
\end{abstract}

Palabras clave: Educación, educación emocional, escolanovismo, escuela tradicional, escuela nueva, neuropedagogía, pedagogía. 


\begin{abstract}
This article presents an analysis of the "traditional" and "new" categories used to explain pedagogical, didactic and educational positions in general. It is based on the hypothesis that, under the false appearance of a debate between conservatism and progressivism, issues that merit a more complex and profound treatment are simplified. The article proposes to recognize the heterogeneity of visions that are presented as
\end{abstract}

"criticisms of traditional education", where the liberating ideals of the newschooling of the early twentieth century coexist with other speeches set forth since the neo-liberal reforms, of efficient, neuroscientific and moralizing features.

Keywords: Education, emotional education, new-schooling, traditional school, new school, neuropedagogy, pedagogy.

\section{Las críticas a la "escuela tradicional"}

Propondremos aquí abordar la cuestión del contraste entre lo nuevo y lo tradicional en educación. Pero no trazando una semblanza de lo nuevo ni procurando despertar a los maestros tradicionalistas para que se asuman, de una vez por todas, partidarios de lo nuevo y echen mano de todo aquello que traen los aires de cambio. Más bien, todo lo contrario. La idea que se ubica en el centro del texto es prácticamente opuesta a ese elogio de lo nuevo. Lo que se propone es salir del espejismo que se dibuja sobre la dicotomía nuevo/tradicional, y también reconocer la heterogeneidad que se oculta tras esa distinción binaria. Detrás del título de "lo nuevo", especialmente, se encuentran posturas totalmente antagónicas que, en su coral oposición a lo tradicional, pueden ser confundidas o llegar a mimetizarse. Uno de los propósitos de este trabajo es, entonces, recorrer la dicotomía nuevo/tradicional para desarmarla y para reconocer, de cada lado, algunas cuestiones que ameritan ser señaladas.

Los conceptos de "nuevo" y “tradicional” son empleados en los debates pedagógicos y didácticos para hacer referencia a dos conjuntos de ideas -más o menos enfrentadas, más o menos opuestas entre sí- que con mucha frecuencia se representan bajo la forma de un esquema binario, donde las ideas propias de cada concepción se oponen a sus correlativas al otro lado de la línea. Es probable que en la mayor parte de los cursos iniciales de pedagogía, en algún momento el profesor a cargo divida el pizarrón en dos y esboce alguna versión de este esquema. Por un lado, se exponen los principios del dispositivo escolar, el mecanismo de la escolarización que nos remonta al surgimiento de los sistemas educativos modernos. Por otro lado, se proponen principios superadores de aquel dispositivo, con ideas 'nuevas' identificadas con distintas corrientes pedagógicas del siglo XX. Se trata de un ejercicio que en general resulta interesante y fructífero, ya que invita a recorrer hitos históricos, didácticos, pedagógicos y políticos, especialmente cuando se trata de comenzar a desnaturalizar los dispositivos escolares para poder verlos como un campo en disputa, como un terreno de debates. Un ejemplo de este clásico cuadro se expone en la Tabla 1. 
Tabla 1. Pedagogía “tradicional” vs. pedagogía "nueva”

\begin{tabular}{|c|c|}
\hline Pedagogía "tradicional" & Pedagogía "nueva" \\
\hline $\begin{array}{l}\text { Centrada en el programa y en las } \\
\text { explicaciones del docente. }\end{array}$ & Centrada en los intereses de los alumnos. \\
\hline Piensa en un alumno pasivo, receptor. & $\begin{array}{l}\text { Piensa en un alumno activo, constructor del } \\
\text { conocimiento. }\end{array}$ \\
\hline Verbalista, libresca. & $\begin{array}{l}\text { Dedicada a explorar distintos lenguajes y } \\
\text { modos de conocer. }\end{array}$ \\
\hline Jerarquiza lo conceptual, lo intelectual. & Jerarquiza lo afectivo, la imaginación. \\
\hline $\begin{array}{c}\text { Apunta al registro, la memoria, el acopio, lo } \\
\text { reproductivo. }\end{array}$ & $\begin{array}{c}\text { Apunta a la relación creativa, productiva, } \\
\text { abierta con el saber. }\end{array}$ \\
\hline $\begin{array}{l}\text { La disciplina es impuesta, como una } \\
\text { condición necesaria para la enseñanza. }\end{array}$ & $\begin{array}{l}\text { La disciplina es una construcción de los } \\
\text { alumnos, es una "autodisciplina". }\end{array}$ \\
\hline $\begin{array}{l}\text { Hay un interés en el logro de resultados } \\
\text { medibles. }\end{array}$ & Hay un compromiso con los procesos. \\
\hline $\begin{array}{l}\text { La enseñanza responde a métodos } \\
\text { que dictan una serie de pasos a seguir, } \\
\text { preestablecidos. }\end{array}$ & $\begin{array}{l}\text { La enseñanza se concibe en forma } \\
\text { estratégica, donde las acciones se amoldan a } \\
\text { lo imprevisible de las situaciones. }\end{array}$ \\
\hline La planificación es una tarea técnica. & La planificación es un ejercicio creativo. \\
\hline $\begin{array}{c}\text { La evaluación se materializa en exámenes } \\
\text { y otros dispositivos experimentales } \\
\text { destinados a la medición. }\end{array}$ & $\begin{array}{c}\text { La evaluación se materializa en propuestas } \\
\text { dinámicas, de producción abierta, } \\
\text { destinadas a la reflexión sobre los procesos } \\
\text { de aprendizaje. }\end{array}$ \\
\hline $\begin{array}{c}\text { El grupo de alumnos es considerado en } \\
\text { forma homogénea, sin considerar las } \\
\text { diferencias. }\end{array}$ & $\begin{array}{l}\text { Los estudiantes son vistos atendiendo a sus } \\
\text { particularidades. }\end{array}$ \\
\hline
\end{tabular}

El esquema, así planteado, propone un universo dividido muy nítidamente entre dos conjuntos de argumentos. Unos conservadores, otros progresistas. Unos apegados al hábito y lo consolidado, otros a la innovación y la creatividad. Unos aburridos, descomprometidos, mecánicos. Otros entusiastas, vocacionales y disruptivos. Unos “conductistas" y otros “constructivistas". Así presentado, el mundo de la pedagogía se divide en "buenos" y "malos" muy claros y establecidos, y los desafíos del buen docente se limitan a apegarse lo mejor posible a los principios del lado derecho de la Tabla. Deberá sortear, claro, la "resistencia al cambio", los "hábitos profesionales" y otros demonios que impiden a la nueva pedagogía manifestarse en todo su esplendor, pero finalmente todo se trata de elegir el lado indicado y tener el coraje de ocuparlo. Al situarse en el territorio de lo nuevo, además, será conceptuado como un docente moderno, actualizado y hasta innovador.

Este esquema, sin embargo, no es transparente. No necesariamente representa la complejidad de las ideas educativas que pone enfrentadas, como tampoco considera otros dilemas pedagógicos y políticos que las atraviesan. Como afirma Cucuzza 
(2017, p.313), “así como ‘escuela nueva’ no es un bloque homogéneo tampoco lo es 'escuela tradicional'; ambos términos de algunos cuadros de doble entrada suelen reducir la complejidad”.

Vale la pena entonces proponer algunos interrogantes para adentrarnos en las cuestiones que, desde esta formulación, no logran terminar de pensarse. La hiperpresencia de esta dicotomía entre lo nuevo y lo tradicional en los discursos pedagógicos, se sostendrá aquí, no contribuye al planteo de problemas centrales ligados a los modos en que los educadores asumimos un compromiso con nuestro oficio y nuestra tarea, y obstruye el tratamiento profundo de problemas emergentes, como la cuestión de las diferencias o el lugar de las tecnologías. Intentaremos entonces apuntar algunas observaciones alrededor de la cuestión, y plantear una serie de hipótesis que podrían ayudar a entender qué decimos actualmente cuando empleamos las palabras "nuevo” y “tradicional” para hablar de educación.

\section{Más allá de lo nuevo y lo tradicional}

La referencia teórica e histórica más evidente detrás de la dicotomía nuevo/ tradicional es, por supuesto, el movimiento de la Escuela Nueva, aquel conjunto de debates y propuestas sobre la forma escolar, la ética de las relaciones educativas y los dispositivos didácticos, que tuvo lugar entre fines del siglo XIX y las primeras décadas del XX. Formaron parte de este movimiento autores de distintas geografías - muchos de ellos latinoamericanos - reunidos en un enorme y potente espíritu de renovación de lo escolar.

[Se trató de] una filosofía educacional que expandió nuevas consignas pedagógicas basadas en la experimentación en el plano de la enseñanza, la puesta en obra de metodologías renovadoras y la impronta de corrientes psicológicas [...], que pretendió superar el disciplinamiento de la clase y el enciclopedismo en la transmisión de conocimientos, característicos de la denominada 'educación tradicional', y se hizo sentir, con diversos grados de intensidad, en la mayor parte de los países de América Latina. (Jafella, 2002, p. 334)

La Escuela Nueva, por otro lado, "no es un sistema didáctico determinado, sino un conjunto de principios tendiente a rever las formas tradicionales de la enseñanza" (Arrondo, 2004, p. 8). A lo largo del siglo XX, además, las ideas escolanovistas se entrelazaron con las pedagogías críticas, el constructivismo y el reproductivismo, y fueron dando forma a un discurso progresista que, sin dejar de identificarse con el escolanovismo, trasciende ampliamente sus postulados originales.

La lista de referentes es larga. Sólo su enunciado demandaría una tarea inmensa de recopilación, a la que no nos dedicaremos aquí. Pero baste decir que si esta compilación de autores escolanovistas tuviera que mostrarse apretadísima en un solo párrafo, no dejaría de mencionar las críticas ácidas de Ferriére a la inmovilidad del aula; los cien lenguajes del niño a los que procuraba dar lugar Malaguzzi; la idea de una sociedad 
educadora pero desescolarizada de Illich; la búsqueda de formas de educar basadas en la autonomía y la confianza en el niño de Montessori; la búsqueda de una enseñanza sensible a la plasticidad y las necesidades del niño de Claparede; el experimento escolar libertario de Neill en Summerhill, donde las asambleas reemplazan a la disciplina y se educa para la autodeterminación; la convicción de las hermanas Agazzi de preparar para la vida haciendo vivir; el credo pedagógico de Dewey, crítico de las materias escolares y pensador de la escuela como espacio democratizador; la escuela sin timbres de las hermanas Cossettini, donde se buscó recuperar el lenguaje espontáneo de la infancia; las experiencias de periódicos escolares y de métodos alternativos de convivencia desarrolladas por Janusz Korczak en pleno gueto de Varsovia; la pedagogía cooperativa y popular de Freinet; la pedagogía de la individualidad de Pakhurst; las experiencias de educación y trabajo de Jesualdo Sosa; las críticas a la enseñanza memorística y la reforma educativa científica, tecnológica y democrática de Anisio Teixeira; las pedagogías antiautoritarias de Tolstoi y de Makarenko; y una extensa lista de otros nombres entre los que no faltan Kilpatrick, Cousinet, Rezzano, Fossati o el propio Paulo Freire, entre muchos otros. ${ }^{2}$

Ahora bien, repasando las biografías de estos autores, si algo puede decirse de inmediato con respecto a la escuela nueva es que sus ideas están cumpliendo un siglo de vida. Si se consideran, además, varios antecedentes de los planteos escolanovistas en autores de los siglos anteriores - como Fröebel, Rousseau o Pestalozzi- la edad del escolanovismo es aún mayor ${ }^{3}$. Es cierto, como escribió Lourenco Filho, que si acaso "no existe institución más antigua que la de educar, puede asegurarse también que no hay novedad más vieja que la de la Escuela Nueva” (citado en Marín Ibáñez, 1976, p. 23). Y por eso mismo es imprescindible señalar el falso carácter de nuevas, en un sentido estricto, de las voces que proponen revisar el mundo de la educación tradicional.

En este marco, cabe preguntarse: si se trata de ideas antiguas que han sido vueltas a formular tantas veces, ¿por qué estas ideas siguen siendo consideradas "nuevas”? ¿Por qué siguen ocupando caprichosamente la mitad derecha de ese remanido esquema, reproducido hasta el hartazgo en manuales de pedagogía y congresos pedagógicos, pero también en memes y redes sociales? Y sobre todo: ¿Cómo es que, habiendo un consenso tan nítido respecto de la conveniencia de adoptar el espíritu escolanovista

\footnotetext{
2. Un buen repaso reciente de ideas de autores de la escuela activa puede verse en Meirieu, P. (2016). Recuperar la pedagogía. De lugares comunes a conceptos claves. Paidós Argentina. Dos excelentes fuentes de material biográfico sobre estos autores son, por otro lado, la serie Maestros de América, de Unipe (donde pueden verse semblanzas en video de pedagogos latinoamericanos, como Paulo Freire, Gabriela Mistral, Jesualdo Sosa, Simón Rodríguez y José Martí, entre otros) y las biografías de IBE-Unesco, donde hay una larguísima lista de autores cuyas biografías se presentan en artículos muy bien escritos. Ver serie Maestros de América en https://www.youtube.com/playlist?list=PLJtilfDswj1dFoZIHPhq808KAi_HxGfI5 Biografías de la revista trimestral de educación comparada (París, UNESCO: Oficina Internacional de Educación) en http://www.ibe.unesco.org/es/documento/pensadores-en-educaci\%C3\%B3n

3. Como señala Paola Varela: “A pesar de la autoatribución de novedad, el movimiento pedagógico de Escuela Nueva no surgió de modo espontáneo y abrupto, puesto que el capital cultural se va renovando, pero sobre la base de conocimientos precedentes. Dos pedagogos decimononos vendrían a tener gran influencia sobre los principios de puerocentrismo y educación para la vida; los aportes del suizo-italiano Pestalozzi (1746-1827) y del alemán Fröebel (1782-1852) se convirtieron en fundamentales para la pedagogía contemporánea" (2011, p. 82).
} 
en la escuela, las prácticas escolares siguen siendo percibidas, en gran medida, como tradicionales? ¿No nos hemos convencido todavía de las virtudes de lo nuevo frente a lo tradicional?

Sostendremos aquí que la oposición nuevo/tradicional no es, hoy, eje de un debate pedagógico transparente sino el camuflaje de otros problemas que, ocultos tras esa simplificación, no terminan de emerger. Por otra parte, y como enseguida veremos, las críticas a la escuela tradicional no son necesariamente revisiones progresistas que reivindican prácticas más libertarias. Sostenemos una hipótesis respecto del sentido actual del debate entre la educación tradicional y la educación nueva, al que reconoceremos como escindido en significados ambivalentes. Diremos entonces que existen al menos dos posiciones que se asumen como críticas de lo tradicional: está la vieja escuela nueva (la de los escolanovistas de comienzos del siglo XX), con sus principios plasmados en aquellos antiguos documentos y que ha ido dejando herederos notables en referentes más recientes, en las pedagogías críticas y en el constructivismo; y hay, por otro lado, un abanico de corrientes que se manifiestan como críticas a la escuela tradicional, pero que no necesariamente se inspiran en los mismos ideales.

Se puede observar cómo ciertas críticas a la escuela tradicional, que fueron usualmente esgrimidas por los educadores marxistas o los promotores de escuelas de formatos alternativos, reaparecen en la actualidad como argumentos para la modernización liberal, la denostación del lugar del maestroy la promoción de modelos neurocientíficos o moralizantes. Podríamos hablar, para nombrar a estas corrientes de algún modo, de un escolanovismo emancipador, y de una especie de escolanovismo de mercado. O de una vieja escuela nueva y una reversión de la escuela nueva, que bajo el estruendo de las críticas al enciclopedismo y a la clase expositiva, intervienen con un arsenal propositivo que reedita parte del eficientismo y el espíritu tecnicista más tradicional, en cóctel con nuevos movimientos emergentes como las neurociencias y la educación emocional, con las prescripciones de los organismos internacionales y con el lenguaje propio del ámbito de la gestión empresarial, el coaching y hasta la autoayuda.

Este "escolanovismo de mercado", lo es en dos sentidos diferentes. Por un lado, porque se apoya en el bum comercial de toda una serie de métodos, productos, manuales, videos, etc., que prometen al maestro mejorar o facilitar sus prácticas por medio de técnicas ligadas a la neurociencia, la inteligencia emocional o la gestión del conocimiento. Por otro lado, porque es funcional a las políticas educativas del neoliberalismo aggiornado ${ }^{4}$ del siglo XXI y a los discursos pedagógicos impulsados por la OCDE, el Banco Mundial, el BID, etc., donde se busca hacer convivir una crítica a lo tradicional, con una "solución" solidaria con

4. Aggiornado: término empleado en Argentina proveniente del italiano Aggiornare (Actualizar). Se encuentran versiones españolizadas como agiornado y ayiornado. (N. del E.) 
[...] estilos de gestión y administración provenientes del sector empresarial, la presencia de CEO's de empresas y funcionarios formados en instituciones privadas en la gestión de programas y proyectos del sector público, y un mayor énfasis en el establecimiento de estándares y medidas de desempeño como solución a los problemas del sistema. (Feldfeber, Puiggros, Robertson, y Duhalde , 2018, p. 91)

A ello se suma el lugar protagónico otorgado a las ONG, la orientación de la educación hacia el mercado, la centralidad de las evaluaciones estandarizadas y las pruebas PISA, "la promoción de valores como el liderazgo, el cambio y la innovación como sinónimos de mejora, el emprendedorismo, la meritocracia, y la rendición de cuentas (acountability) a partir de la medición y evaluación de resultados a través de pruebas estandarizadas" (Feldfeber et al., p. 91), además de la apertura del sistema educativo para negocios privados y la impugnación y el progresivo desmantelamiento de discursos, legislaciones y organismos de gobiernos pasados dedicados a la promoción de derechos educativos. Estas políticas demandan una pedagogía que les sea solidaria. Y esa pedagogía, a la que aquí llamaremos "escolanovismo de mercado" (y reconózcase el tono cínico, pues de escolanovismo, como veremos, no tiene nada), se ha acomodado del lado de lo "nuevo" y ha hecho propias las críticas a lo tradicional.

Si se presta atención a las transformaciones recientes que se han ido operando en el lenguaje disponible para hablar de la educación en términos progresistas, se verá que parte del lenguaje con el que se critica a la escuela tradicional ha ido renovando su vocabulario para dejar atrás los términos propios del escolanovismo emancipador, y hacer propios los del escolanovismo de mercado. De la libertad, la individualidad y la autodeterminación, al emprendedurismo, la innovación y la neuropedagogía. Del maestro como emancipador, al maestro como líder o facilitador. De la escuela como espacio de construcción colectiva, a la escuela como espacio de gestión de la calidad. Estos fenómenos discursivos muestran así la apropiación del espacio de la crítica a lo tradicional por parte de actores impensados: los promotores del gerencialismo y de la mercantilización de la educación.

\section{Del otro lado del cuadro, inmutable, la escuela "tradicional" recibe las bofetadas.}

Se adivina entonces un nuevo cuadro dicotómico, hecho no ya de tradicionales y nuevos, sino de nuevos de antes y nuevos emergentes, de viejos nuevos y de nuevos viejos, donde los contrastes son notorios. Quizás el más visible es el que se demarca desde el sentido histórico de las críticas a la escuela, y desde el discurso de la crítica a lo tradicional. El escolanovismo que convivía con las vanguardias políticas y artísticas de comienzos del siglo XX planteaba una crítica a la escuela tradicional en un contexto altamente estatalizado, donde las funciones sociales de la escuela se daban más o menos por hechas, y donde lo que se requería era cuidar a los chicos de los "efectos secundarios" de la escolarización. Las nuevas críticas a la escuela tradicional, en cambio, se formulan en la sociedad de consumo hipermercantilizada del siglo XXI, marcada además por cierta fragilidad institucional de la escuela. Y en ese marco, las críticas atacan justo lo que no 
se debería atacar: la función social de la escuela, su carácter público.

Por todo lo dicho, la distinción nuevo vs. tradicional presentada como un supuesto genérico de partida, como algo dado por hecho (y a partir de la cual se puede seguir pensando) en este contexto, no sólo simplifica un debate pedagógico que es complejo y demanda una visión más amplia y completa, sino que superpone y mimetiza falazmente posiciones muy contrastantes entre sí. Se ofrecen a continuación algunas reflexiones e hipótesis, emparentadas tal vez de distintas maneras con la distinción nuevo/tradicional, que se proponen alumbrar otros aspectos del hecho educativo que no son tan claros desde aquélla, y desde las que se pueden analizar algunas de las ideas y palabras que están disponibles hoy para nombrar y pensar la educación. Nos detendremos, puntualmente, en dos de los bastiones discursivos y metodológicos de estas nuevas propuestas: la neuropedagogía y la educación emocional.

\section{Del empoderamiento del alumno, a la "revolución del cerebro"}

Uno de los gestos característicos de la escuela nueva ha sido el de recuperar y empoderar el lugar del alumno. Aquel alumno, olvidado por las pedagogías científicas que se centraron exclusivamente en el docente, y pretendieron trasladar al terreno de la educación cierta racionalidad metódica, de corte mecanicista, aparece en los textos escolanovistas como protagonista, punto de partida y punto de llegada de la educación. Este excesivo centramiento de la enseñanza en el docente fue blanco de las críticas escolanovistas, que "descubrieron" al niño, lo que dio lugar a un interés en la infancia que no tenía precedentes en la historia de la humanidad. La escuela nueva es escuela activa, precisamente por la actividad del niño. Calvache López (2014), en su repaso de los principios rectores del movimiento, señala la actividad, es decir, el interés por situar al alumno en una actitud activa frente al aprendizaje, como el primero y más importante, junto con otros como la globalización de contenidos, la individualización, etc. Estimular la actividad del niño, dice Marín Ibáñez,

se ha convertido ya en tópico para todas las corrientes pedagógicas. Para muchos, escuela nueva y escuela activa acaban confundiendo sus perfiles, entre otras razones porque el propio Ferrière publicaría sus obras bajo la divisa indistinta de escuela nueva y escuela activa. (1976, p. 39)

En un sentido más amplio, el lugar central de la infancia en la pedagogía ha caracterizado el siglo XX. Las psicologías infantiles, el lugar constitutivo de la infancia en el psicoanálisis (donde la experiencia psíquica del niño es la mismísima explicación del psiquismo adulto), la emergencia de espacios, productos y estéticas de lo infantil cada vez más específicas y sofisticadas, todo ello permitió definir al siglo XX como “el siglo del niño", sin que la expresión sea, en absoluto, exagerada. En su libro de 1900 titulado precisamente El siglo del niño, Ellen Key anticipa el lugar que tendría la infancia en la agenda contemporánea, una infancia oprimida por la institución familiar y la escuela a la que hay que liberar de sus amarras (cf. Galvis, 2009). Y descubrir al niño significó descubrir su "naturaleza", las leyes que rigen su pensamiento, su imaginación y sus juegos. Como describía Malaguzzi con su metáfora de los "cien 
lenguajes" del niño (de los que noventa y nueve le son robados), descubrir al niño es descubrir todo aquello oculto y negado, sus códigos y sus sensibilidades. Aun antes, a fines del siglo XIX, Janusz Korczak escribía en un periódico escolar:

Los nombres de Pestalozzi, Froebel y Spencer tienen tanta importancia como los de los inventores que anuncian el siglo XX. Lo que han descubierto es mucho más que las fuerzas desconocidas de la naturaleza; han descubierto la mitad desconocida de la humanidad: los niños. (Lewowicky, 1994)

Este gesto político, que consistió en poner toda la atención en los niños y destronar la dictadura del método y de la racionalidad adulta, constituyó una verdadera revolución pedagógica y devino en propuestas de enseñanza y de organización escolar disruptivas que siguen ensayándose, como aquellas conocidas hoy como "pedagogías alternativas" y asociadas a la visión de Montessori, de la corriente Waldorf, etc.

Ahora bien, examinemos la versión mercantilizada de esta idea del centramiento en el niño, que ha encontrado su expresión máxima en las "neuropedagogías" que, aunque tienen muy poco que ver con los principios escolanovistas, curiosamente se postulan como una revolución educativa (Brailovsky, 2016). Muchos de los textos que hablan de neurociencias y educación se suponen portadores de visiones críticas acerca de la escuela tradicional, y hasta se autoproclaman revolucionarios. "La revolución del cerebro", "la nueva educación basada en el cerebro" o "la revolución de la neuropedagogía”, son algunos de los estandartes que sostienen. De manera general, suponen que el enfoque neuronal podría servir para resolver incluso el problema de la pobreza. Daniel Korinfeld lo explica así (Rezzónico, 2017):

La noción de "capital mental” o "la cuenta bancaria de la mente, que se debita o acredita a lo largo del ciclo de vida, desde la infancia hasta la vejez" son algo más que simpáticas metáforas economicistas ya que algunos autores llegan a afirmar, sin ruborizarse, que la pobreza impide la función cognitiva y un modo de superarla es a través de una terapia cognitivo conductual que mejoraría su "capital mental".

Suponen que los hallazgos en materia de neurobiología aportan a la pedagogía lo bastante como para considerarse revolucionarios, y que la asombrosa posibilidad de observar mediante complejas tecnologías el funcionamiento de un cerebro vivo, que es fascinante, se traduce en revoluciones educativas. Para Paniagua, por ejemplo, la neurociencia

crea una nueva forma de ver la educación, la Neurodidáctica, que analiza las competencias que el cerebro tiene, que se llega a la comprensión de la diversidad personal en el proceso del aprendizaje [...]. El cambio fundamental dentro de la educación, es que el educador, asuma un nuevo rol y se prepare para accionar desde esta nueva postura, [donde] el educador es un modificador cerebral, que puede cambiar con su práctica, la estructura, la química y la actividad eléctrica del cerebro. (Paniagua, 2013, p. 72) 
Este exabrupto de trasladar los hallazgos de la neurobiología, sin mediaciones, al terreno escolar, es posible porque absorbe el discurso del escolanovismo en lo que se refiere al empoderamiento del niño, aunque desconoce en gran medida el sentido educativo de ese gesto. Conocer al niño, sus potencias, su lugar en el mundo, para respetarlo y empoderarlo, se convierte aquí en "conocer su cerebro".

La evidencia más cabal de esta apropiación falaz de los argumentos escolanovistas por parte de la neuropedagogía, es el hecho de que los manifiestos escolanovistas de principios del siglo XX ya expresaban (mucho antes de las resonancias ylas tomografías, y de un modo mucho más ordenado y elocuente) muchos principios prácticos que hoy proclama (en forma mucho más precaria) la neuropedagogía, como la necesidad de atender a las individualidades, evitar las actividades descontextualizadas o promover la investigación. Una excelente recopilación de estas ideas clásicas puede hallarse en el libro más reciente de Philippe Meirieu, donde el punto de partida es su cólera hacia los panfletos que difunden ideas clásicas de la educación nueva, presentándolas como paquetes fáciles de vender (Meirieu, 2016). El texto de Meirieu es apenas un ejemplo para mostrar que son muchos en todo el mundo los que observan con preocupación cómo los gurúes mediáticos del momento presentan, simplificadas y vulgarizadas, ideas que ameritan pensarse mejor. Otro ejemplo elocuente es el ensalzamiento que se hace de las propuestas "revolucionarias" de Sir Ken Robinson sobre la creatividad, que en parte simplifican y en parte ignoran todo lo dicho acerca de la cuestión, pero cuya popularidad en YouTube y la proyección de su éxito en el área del management y los recursos humanos, lo ha convertido en todo un referente sobre el tema.

La neuropedagogía retoma la crítica al excesivo centramiento de la enseñanza en la figura del docente, que explica y despliega sus saberes sin tener en cuenta los intereses auténticos y las necesidades de los alumnos, que quedan relegados a una posición de espectadores pasivos. Ahora bien, algunos partidarios de los enfoques neuropedagógicos suponen que conocer mejor el cerebro equivale a conocer mejor al alumno y sus potencialidades, y creen que este conocimiento devendrá en una revitalización del olvidado lugar del estudiante en el aula. Sin embargo, en este razonamiento hay una falacia evidente: las razones del olvido del lugar del alumno no pueden buscarse sólo ni principalmente en los misterios del cerebro. No sólo porque el organismo no es el cuerpo, sino porque este dilema educativo tiene explicaciones mucho menos lineales, que es preciso mirar pedagógicamente.

Mirar el cerebro no es mirar al alumno, pues el alumno es en situación y en relación. Conocer científicamente el cerebro no equivale a conocer científicamente el aprendizaje. E incluso si lo fuera, poner la lupa sobre los mecanismos del aprendizaje no es el único modo (ni el mejor, probablemente) de mejorar la enseñanza. Las neurociencias que miran la educación con la esperanza de revolucionarla emplean la expresión "enseñanza basada en el cerebro". El punto de partida, dicen, debe ser un conocimiento más detallado de los mecanismos del aprendizaje. Y los argumentos que se utilizan, en general, son parecidos a los de la psicología evolutiva clásica: "si entendemos cómo funciona la mente, educaremos mejor". En ambos casos, el riesgo es similar: se intentan reemplazar los esfuerzos que demandan las relaciones 
educativas (complejas, cambiantes, políticas, insertas en instituciones) por fórmulas esenciales sobre "el alumno" o "el aprendizaje".

Desde un lugar muy diferente, el escolanovismo y las pedagogías críticas sostienen que el punto de partida de la enseñanza es el marco cultural, ideológico, político y social de los alumnos. Conocer al alumno no es conocer su cerebro, en este caso, sino conocer sus circunstancias, ahondar en los rasgos de lo infantil. Esta idea se reafirma desde muchos ángulos, incluidas las nuevas visiones psicológicas sobre el aprendizaje, representadas en las lecturas actuales de la teoría sociohistórica de Lev Vygotski, donde el aprendizaje no es escindido de las relaciones sociales en las que tiene lugar. Desde esa visión, está claro que no hay recetas ni verdades absolutas. Hay que saber mirar, y desarrollar en forma más artesanal que metódica una mirada sensible sobre las relaciones que se van tejiendo en la trama de lo educativo. Y aunque esta idea es más o menos incompatible con la que sostiene que el punto de partida de la educación es el conocimiento del cerebro, paradójicamente muchos autores de la corriente neurocientífica se dicen afines a las pedagogías críticas y a la corriente de la escuela nueva. Toman el principio escolanovista de "descubrir al niño" como un eslogan vacío pero oportuno, y lo ponen al servicio de un suculento mercado de libros, videos y métodos sobre el cerebro que ha desbordado las ventas en locales comerciales diversos.

Los conocimientos científicos acerca del aprendizaje siempre han sido un insumo del trabajo escolar. Sirven para acompañar hipótesis de trabajo de los docentes y para brindarles una formación amplia y general. Pero no son el único modo de fortalecer el lugar de los alumnos en las relaciones educativas. Y no lo son, porque en lugar de acercar a maestros y alumnos en una relación más libre, más sincera y más comprometida, estos saberes (psicológicos o neurocientíficos) ponen el aprendizaje y la enseñanza en lugares rígidos y supuestamente asépticos. Puede ser útil saber qué límites impone la biología a los tiempos de un bebé, por ejemplo, o cada cuántos minutos la mente debe descansar, o cuán necesaria es la hidratación para prestar atención. Pero lo cierto es que las acciones de los maestros se significan en sus relaciones con los alumnos, y no hay un modo de estandarizar ni medir en forma absoluta sus efectos.

En su profundo análisis de la cuestión, Terigi observa que "desde el punto de vista de la educación escolar es tan absurdo 'adherir' a las neurociencias como "oponerse” a ellas, porque no se trata de un discurso de opinión” (2016, p. 51). Sin embargo, continúa:

Cuando los investigadores en neurociencias realizan afirmaciones sobre el aprendizaje humano con base en sus estudios, corresponde examinar el alcance de esas afirmaciones y su validez fuera del ámbito del laboratorio o la clínica, y cuando se extienden hacia recomendaciones o aun prescripciones para la práctica escolar, corresponde a educadores, psicólogos y pedagogos delimitar de qué tipo de aportes se trata, situar los alcances y límites de los aportes de estas disciplinas para comprender el aprendizaje escolar, y advertir sobre los problemas de una inadecuada extensión de los alcances de los resultados de investigación. (2016, p. 51) 
En ese sentido, una cuestión que vale la pena mencionar tiene que ver con el modo en que los neurólogos ven la educación a la hora de realizarle sus aportes. El fenómeno de las neurociencias en educación es uno de orden discursivo, con todo lo que ello implica: tribus que crean y habitan sus jergas, y lenguajes que, al decir de Foucault, tallan los objetos que nombran. En ese punto, el cruce entre ambas disciplinas (neurobiología y pedagogía) se funda en una serie de malentendidos, el primero de los cuales es la visión deformada que cada una tiene de la otra. Muchos educadores aceptan con demasiada confianza todo lo que proviene de las investigaciones neurológicas, tal vez por la legitimidad que brinda per se el discurso médico: ¿quién se va a oponer a tomar aquello que los científicos descubren como plataforma de la enseñanza, con lo serios y asépticos que se ven en sus delantales? Los expertos en neurociencias, por su parte, tienen en general una visión algo simplificada de lo que significa educar. Los relatos de sus experiencias en la escuela y algunas estadísticas generales suelen ser toda la evidencia que aportan para reconocer en la escuela un recipiente ideal de los avances en las investigaciones. Los reduccionismos a ambos lados de la relación, entonces, no ayudan.

Finalmente, lo que parece haber detrás de esta euforia por los avances neurocientíficos como panaceas capaces de revolucionar la educación, es la vieja idea iluminista del progreso, siempre solidaria con los afanes de control. Por eso, desde una visión crítica parece improbable que los aportes de las neurociencias a la educación constituyan algún tipo de revolución copernicana para la educación, la enseñanza y las prácticas escolares. Los modos de la educación de cambiar de paradigma, de atravesar sus "revoluciones", en general tienen que ver con cosas pequeñas, pero muy trascendentes: cómo establecemos una conversación maestros y alumnos, cuánto y cómo sabemos escucharnos, cómo imaginamos el futuro común, qué permisos habilitamos para ser uno mismo dentro del aula, y cómo conciliamos las demandas que la enseñanza presenta a nivel de las relaciones individuales y de las utopías sociales.

\section{Del humanismo a la autorregulación emocional}

Entre los principios escolanovistas, el de humanizar las relaciones y dar lugar a la vida afectiva y a los sentimientos aparece como una respuesta a la excesiva racionalidad de la vida escolar. Como sucedió con prácticamente todas las ciencias sociales, también la educación, en cierta medida, asumió algunos principios de la racionalidad científica más dura para legitimarse como disciplina. La búsqueda de métodos de enseñanza, de teorías sobre el aprendizaje, de visiones estructuralistas y funcionalistas sobre el funcionamiento de la educación y de las escuelas, llevó a lo que más adelante tendría su expresión máxima en la llamada "pedagogía tecnicista”, que hace de la planificación racional y sistemática un principio totalizador. La escuela tradicional, podría decirse, es una escuela racional y científica. La escuela nueva, sin dejar de asumirse científica, convivió con enfoques más espiritualistas y observó con preocupación el sesgo mecanicista de los métodos tradicionales, a los que sistemáticamente cuestiona. Aun tratándose de un movimiento metódico y científico, hizo suya una ética y una filosofía desde las cuales dedicó una cuantas páginas a procurar humanizar y ablandar ese imaginario tan racionalista. Adolphe Ferière, uno de los grandes referentes de esta 
corriente, es autor de un breve poema que se convirtió en todo un ícono de las críticas a la escuela tradicional: Y siguiendo las indicaciones del diablo, se creó la escuela. Y allí dice:

El niño ama la naturaleza, se lo hacinó en aulas cerradas. [...] Le encanta moverse, se le obligó a permanecer inmóvil. Es feliz manipulando objetos, se le puso en contacto con las ideas. Ama usar las manos, se le pidió que sólo usara el cerebro [...].

La idea de una oposición entre la razón y la emoción aparece en distintos autores de esta corriente. En menor medida expresada como una atención dirigida hacia la afectividad del niño como un objeto necesario de estudio del educador; más frecuentemente, como un principio filosófico que orienta la tarea, y según el cual se ve al niño en su totalidad, como un sujeto integral, no reducido a su actividad racional. Se plantea la idea de individualidad, entendida no desde la resonancia actual del término como personalismo, sino como cierta forma de singularidad holística. La escuela nueva, afirma Flórez Ochoa, "parte de una concepción antropológica moderna, de una ética de la libertad relativista y pragmática, de una concepción holística biosicosocial del niño" (1995, p. 203). El principio de individualidad, dentro de esta concepción, supone que

[...] no existen individuos abstractos ni promedios, el individuo siempre es concreto, Pedro, María, cada uno con su interioridad, sensibilidad, energía, afectos, experiencias, aptitudes, estilo y ritmo personal de hablar y pensar, ideas, sueños, proyecciones personales (y familiares) etc., que imbricados constituyen la individualidad a la que tendrían que atender, asistir y promover tanto el buen profesor como la buena enseñanza. (Flórez, 1995, p. 210)

Hay, en suma, en la visión del escolanovismo emancipador, una valoración integral del niño que confronta la idea del sujeto del aprendizaje como un ser racional idealizado, pasible de contener procesos tipificados y transparentes. Y dentro de esta visión, la idea de dar cabida a los afectos tiene un lugar natural y evidente. Como nota interesante dentro de esta caracterización, Dussel señala que la Escuela Nueva

[...] propuso un equilibrio distinto con la dimensión afectiva. Pero en muchos casos primó una versión medicalizada de los afectos, o biologicista. No casualmente, muchos de los pedagogos escolanovistas eran médicos (como Montessori) o adscribían a visiones "naturalistas" del desarrollo humano (como Piaget). (2006, p. 5)

Ahora bien, del mismo modo que la neuropedagogía tomó el principio escolanovista de centramiento en el niño, transformándolo en una nueva versión del cientificismo estigmatizante, existe una forma análoga de apropiación de la concepción holística del niño: la llamada "educación emocional”. Desde esta visión también se critica la idea de que la educación sea vista como una cuestión puramente intelectual, y se 
propone dar relevancia al mundo de las emociones, como un aspecto hasta ahora menoscabado que merece ser puesto al mismo nivel que la racionalidad. La idea se apoya en la tradición escolanovista. La educación emocional hace propia la idea de Malaguzzi según la cual de los cien lenguajes del niño, noventa y nueve le son robados y sólo se le permite el lenguaje de la razón. Y la valoración del mundo emocional es, efectivamente, un punto de partida de esta corriente. Sin embargo, los marcos conceptuales más habituales de la educación emocional se alejan de los ensayos filosóficos, psicoanalíticos o pedagógicos desde los cuales se planteaban estas ideas en la tradición escolanovista. Algunos autores de la educación emocional señalan al escolanovismo como un antecedente importante, pero que no llegó a profundizar lo suficiente la cuestión. Darder, por ejemplo, observa que en el escolanovismo siguió dándose una coexistencia desigual a favor del conocimiento, aunque "la presencia de las emociones - la afectividad era la expresión que se utilizaba entonces- era constante en los propósitos y en las prácticas renovadoras (2006, p. 61).

Se señalan como precursores de la corriente los trabajos de Gardner sobre los distintos tipos de inteligencia, el best seller de Daniel Goleman Inteligencia Emocional, una serie de informes de organismos internacionales que dieron lugar a la cuestión de las emociones (p. ej., el informe Delors a la Unesco, que hace referencia a las ideas de "aprender a ser" y "aprender a convivir"), y obras precursoras como la de Peter Salovey y John Mayer, señalados como antecedente del libro de Goleman, y dedicada al diseño de instrumentos capaces de medir la inteligencia emocional (cf. Darder y Bach, 2006). Comentando el trabajo de estos autores, Fernández y Extremera sostienen lo siguiente:

La escuela del siglo XXI ha asumido y reflejado desde el inicio este debate y se ha comprometido con la doble misión de educar tanto la cabeza como el corazón, lo académico y lo emocional. Con la certeza de que ambos tipos de aprendizajes están inseparablemente interconectados y que se trata de una falsa dicotomía. (2005, p. 61)

Así, las habilidades básicas propias de la inteligencia emocional propuestas por estos autores - "percibir, valorar y expresar emociones con exactitud", "acceder y/o generar sentimientos que faciliten el pensamiento", “comprender emociones/ conocimiento emocional" y "regular las emociones promoviendo un crecimiento emocional” (Mayer y Salovey, 1997) - , dan lugar a todo un programa educativo que busca desarrollarlas, entrenarlas, potenciarlas.

Los métodos se inspiran con mucha frecuencia en conversaciones, análisis de imágenes, reflexiones y meditaciones guiadas, ejercicios del tipo new age, entre otros. Se sostiene que a través de la educación emocional los alumnos deben lograr manejar las emociones de forma apropiada, modular su estado afectivo y, como expresa un documento de capacitación para docentes de 2018: "manteniendo, aumentando o inhibiendo la emoción que se presenta o modificando su intensidad". A estas formas de gobierno de las emociones para potenciar las capacidades adaptativas se 
las describe como "competencias emocionales", y se acompañan de una serie de ejercicios de respiración, postura y realización de bitácoras de emociones, con la finalidad de identificarlas e intervenir apropiadamente sobre ellas. Como referencia del tono de los documentos de trabajo para capacitación docente en esta temática, sirva un fragmento del documento antes mencionado:

"Si te sucede que hasta ahora nunca te lo planteaste, te invitamos a que comiences a transitar este camino de "hacernos bien" y para ello te ofrecemos a continuación algunas actividades para que comiences a explorarlas. Registra en tu bitácora, si notas cambios en tu emocionalidad".

Como puede verse en el ejemplo, el estilo discursivo hace propio el tono de los libros de autoayuda. A continuación, el documento ofrecerá un esquema gráfico compuesto de afirmaciones del orden de "Esperanza (oración)”, “Compasión”, "Ejercicios de respiración” y "Yoga".

En cuanto a sus interlocutores teóricos, predominan los autores americanos del ámbito de la gestión y del coaching, y se esboza desde allí el híbrido de cierta teoría de la "gestión de las emociones", que presenta a los afectos en el lugar de impulsos que se deben regular, en general escindidos de las relaciones o confinados en categorías operacionales como la empatía, la sinergia, etc. En sintonía con este ideario, esta autorregulación emocional está al servicio del mejor aprovechamiento del trabajo docente, entendido como recurso humano. En los términos del mismo documento: “cuanto más feliz sea, más se implicará en la enseñanza. Cuanto más se implique en ella, más fácilmente conseguirá los objetivos propuestos y por ello aumentará su nivel de calidad educativa". La educación emocional, como puede verse, aplica al mundo escolar un estilo de intervención sobre la vida profesional muy similar al que muchos gurúes y coachers implementan con gran éxito en el ámbito corporativo. Nuevamente, aparece nítida la relación entre la pedagogía de mercado, y el mercado mismo.

En el caso de Argentina, se ha promovido por años el ingreso de esta perspectiva al currículum escolar, impulsando la sanción de leyes de educación emocional y promoviendo capacitaciones docentes como la que sirvió de ejemplo párrafos atrás. Al principio esta relación resultaba impensable. Tampoco había, entre estas ideas y el universo pedagógico de corte más académico o profesional, demasiada superficie de contacto. No han abundado los intercambios críticos de ideas entre ellos, del mismo modo tal vez que no hay cruces de la crítica literaria entre la obra de Borges y la de Coelho, por ejemplo: son registros diferentes, dirigidos a ámbitos distintos. Poco a poco, sin embargo, lo que parecía un fenómeno restringido a las fronteras de su éxito comercial fue siendo aceptado por algunos, y con la llegada al poder de gobiernos neoliberales en la región, la educación emocional es hoy tema de cursos y hasta aparece en algunos diseños curriculares.

A esta altura, alguien podría peguntarse: ¿Y cuál es el problema con la educación emocional? ¿Por qué sería, finalmente, problemático que los educadores se inspiren en 
los libros de autoayuda y "gestionen sus emociones”? ¿A quién le haría daño un poco de ejercitación new age en la escuela, o algunos cuentos moralizantes? ¿Qué hay de malo en "perfeccionar" las propias emociones, como propone uno de los especialistas en la materia? La respuesta a esas preguntas es más política que didáctica: pensadas como prácticas particulares y espontáneas, ninguna de esas propuestas hace daño ni resulta cuestionable. Pero sí resultan problemáticas cuando se entiende que estas prácticas llegaron aquí porque fueron impulsadas explícitamente con la finalidad de llevar al plano individual los problemas sociales y responsabilizar a los individuos por los efectos perniciosos de las políticas desigualitarias.

Cuando leemos los documentos de organismos internacionales que impulsan la educación emocional para enseñar a los sujetos a soportar las penurias a las que los somete un sistema social injusto (y esos documentos existen, y son así de explícitos), cuando caemos en la cuenta de que todo esto sirve para adjudicarse el protagonismo del autocontrol y la autofortaleza en detrimento de cualquier desborde de otro tipo, entonces estos simpáticos ejercicios de respiración comienzan a verse cada vez menos inofensivos. "En general, los educadores latinoamericanos consideran que están preparando adecuadamente a los jóvenes para el mercado laboral”, se dice en un artículo del Banco Mundial, "mientras que los empresarios lamentan la falta de habilidades sociales y emocionales”.

Es esclarecedor en ese sentido el trabajo de Abramowski (2018), que ubica claramente "la emergencia de estas políticas educativas en estrecho vínculo con los requerimientos actuales del mundo del trabajo y en consonancia con la llamada emocionalización de lo social" (Abramowski, 2018).

\section{Conclusiones}

Las críticas dirigidas actualmente hacia la escuela como institución, a su lógica de funcionamiento, a sus efectos sobre la vida de las personas y las sociedades, como hemos visto, no se limitan a los planteos escolanovistas. En muchos casos, aunque se formulen desde una visión progresista, ni siquiera coinciden del todo con aquéllos, pues éstos no son un manifiesto único y perdurable, sino un discurso cambiante que se va ajustando a las épocas, las coyunturas, y las distintas expresiones de las prácticas educativas señaladas como tradicionales. La dicotomía nuevo/tradicional confunde, da la sensación de articular dos mundos homogéneos que en realidad no lo son. El empleo del término "nuevo" puede significar libertario, humanista, promotor de autonomía, pero también puede significar ajuste al mercado, sintonía con el marketing de ciertas modas pedagógicas, o innovación. El término "tradicional" también tiene su propio abanico de sentidos. Puede significar autoritario, rígido, dogmático, automatizante, o también ineficiente, inútil, banal. Lo que nos interesa es tomar nota de las formas en que, en nuestros días, estos términos son apropiados eclécticamente por los actores de la educación, justamente para demarcar los bordes políticos de ese eclecticismo discursivo. La distinción que proponemos aquí entre las viejas críticas escolanovistas y las nuevas críticas de mercado, permite avanzar un 
poco en la especificidad de estas miradas, en el caso particular de la educación escolar. Porque se trata de posicionamientos diferentes.

El comentario alrededor de los dos estandartes de las pedagogías gerencialistas sobre los que nos hemos detenido aquí, la neuropedagogía y la educación emocional, son ejemplos de cómo contrastan estos dos universos de revisión de lo tradicional.

En el escolanovismo libertario, el espíritu que acompaña las prácticas, las preocupaciones y el ethos del educador resulta un aspecto esencial para entender el hecho educativo. Por eso los postulados escolanovistas y los estudios críticos tienen en general un tono más filosófico que técnico. Dado que el maestro pertenece a un sistema de enseñanza que condiciona su tarea, además, se lo piensa como funcionario que debe saberse atravesado de institucionalidad. El docente como "intelectual público" (Giroux, 2002) se sabe pensante, y se sabe actor político.

En la visión de mercado de los ataques a la escuela, en cambio, el maestro aparece descrito desde una visión individual. Se piensa a los alumnos en términos de talentos y potencialidades que se deben alentar, poniendo así la competencia meritocrática en el lugar del rol distributivo y social de la educación pública. El escolanovismo de mercado hace un elogio del trabajo autónomo como ideal y formula la aspiración de que cada uno pueda crear su propio futuro, dándole al sentido utópico colectivo de la educación un carácter individual. Por su lado, el docente del escolanovismo de mercado es un emprendedor orientado a una formación empresarial, donde se destaca la búsqueda de la salvación individual en un marco competitivo.

\section{Referencias}

Abramowski, A. (2018) El avance de la educación emocional en la Argentina, Revista Bordes, UNPAZ. Recuperado de http://revistabordes.com.ar/ respiracion-artificial/

Arrondo, C. A. (2004). Una aproximación hacia las ideas de la "Escuela Nueva” en la historia de la Universidad Nacional de La Plata, de Julio Castiñeiras (18971938). Anuario del Instituto de Historia Argentina, (4), 7-29.

Brailovsky, D. (18 de octubre de 2016). "Las neurociencias no revolucionan la educación”. La Izquierda Diario. Recuperado de http://www.laizquierdadiario. com/Las-neurociencias-no-revolucionan-la-educacion

Calvache López, J. E. (2014). La escuela nueva y los conceptos básicos de la educación en el pensamiento de John Dewey: Una aproximación teórica. Revista Historia de la Educación Latinoamericana, (5), 107-126.

Cucuzza, H. R. (2017). Desembarco de la escuela nueva en Buenos Aires: heterogéneas naves en puertos heterogéneos. Revista Brasileira de Pesquisa (Auto) biográfica, 2(5), 310-329.

Darder, P. y Bach, E. (2006). Aportaciones para repensar la teoría y la práctica educativas desde las emociones. Teoría de la Educación. Revista Interuniversitaria, (18) $55-84$. 
Dussel, I. (2006). Del amor y la pedagogía. Notas sobre las dificultades de un vínculo. En G. Frigerio y G. Diker (comps.). Educar: figuras y efectos del amor. Buenos Aires: Del Estante Editorial.

Feldfeber, M., Puiggros, A., Robertson, S. y Duhalde, M. (2018). La privatización educativa en Argentina. Buenos Aires: CTERA.

Fernández B., P. F. y Extremera P., N. (2005). La Inteligencia Emocional y la educación de las emociones desde el Modelo de Mayer y Salovey. Revista Interuniversitaria de Formación del Profesorado, 19(3), 63-93.

Flórez Ochoa, R. (1995). La dimensión pedagógica: formación y escuela nueva en Colombia. Revista Educación y Pedagogía, 7(14-15), 197-219.

Galvis Ortiz, L. (2009). La Convención de los Derechos del Niño veinte años después. Revista Latinoamericana de Ciencias Sociales, Niñez y Juventud, 7(2), 587-619.

Giroux, H. A. (2002). Los profesores como intelectuales públicos. Revista de Pedagogía Crítica Paulo Freire, (1), 21-33.

Jafella, S. A. (2002). Escuela nueva en Argentina y Brasil: retrospectiva de un ideario pedagógico en la formación docente. Revista de Pedagogía, 23(67), 333-344.

Lewowicky, T. (1994). Janusz Korczak (1878-1942). Prospects: The Quarterly Review of Comparative Education, XXIV(1/2), 37-48. Paris, UNESCO: International Bureau of Education. (Perspectivas: revista trimestral de educación comparada, XXIV(1-2), 1994. París, UNESCO: Oficina Internacional de Educación.)

Marín Ibáñez, R. (1976). Los ideales de la escuela nueva. Revista de Educación, (242), 23-42. Madrid.

Meirieu, P. (2016). Recuperar la Pedagogía: de lugares comunes a conceptos claves. Buenos Aires: Paidós.

Paniagua, M. (2013). Neurodidáctica: una nueva forma de hacer educación. Fides et Ratio. Revista de Difusión cultural y científica de la Universidad La Salle en Bolivia, 6(6), 72-77.

Rezzónico, A. (2017, agosto). Neuromanía, educación y neoliberalismo. Entrevista a Daniel Korinfeld. Para Juanito, 5(13) Segunda etapa. Recuperado de http:// www.fls.org.ar/juanito/13/para-juanito_13-web.pdf

Terigi, F. (2016, noviembre). Sobre aprendizaje escolar y neurociencias. Propuesta Educativa, 2(46), 50-64.

Varela, P. (2011, diciembre). Disputas y negociaciones en el campo pedagógico argentino. Influencia de los saberes escolanovistas sobre el sistema educativo público nacional, 1930-1943. Educación, Lenguaje y Sociedad VIII(8), 75-105. 